\title{
PRÁTICAS AMBIENTALMENTE SUSTENTÁVEIS EM GESTÃO DE RESÍDUOS DE SERVIÇOS DE SAÚDE: UMA REVISÃO
}

\section{ENVIRONMENTALLYSUSTAINABLEPRACTICESIN WASTEMANAGEMENTHEALTHSERVICES:AREVIEW}

\author{
MÁRCIA REGINA CORDEIRO DE SOUZA | PUC-PR \\ OSÍRIS CANCIGLIERI JUNIOR, PhD. | PUC-PR
}

\begin{abstract}
RESUMO
O aumento na quantidade dos resíduos de serviços de saúde, aliado à deficiência na gestão destes materiais tem gerado grande preocupação quanto ao impacto negativo na saúde da população e no meio ambiente. Diante deste problema buscou-se conhecer as práticas de gestão de Resíduos de Serviços de Saúde (RSS) desenvolvidas com foco na sustentabilidade, através de uma revisão sistemática, para isso realizou-se a busca através da base de dados do Portal de Periódicos da CAPES (Coordenação de Aperfeiçoamento de Pessoal de Nível Superior). O trabalho permitiu o levantamento de práticas sustentáveis desenvolvidas por diversos atores interessados em minimizar o impacto ambiental gerado pelos RSS no nível hospitalar, regional e nacional. As principais ações envolveram: capacitação, segregação, políticas públicas, tecnologia de tratamento, minimização, reutilização e reciclagem, monitoramento do gerenciamento de RSS, designação de responsável pelas atividades de gestão de RSS e investimento pelos governos, entre outras. Identificou-se a necessidade de maior aprofundamento nas pesquisas que apresentam soluções inovadoras em gestão de RSS e um processo que permita a troca de informações entre instituições e governo para capilarizar as melhores práticas e acelerar o processo de redução do impacto ambiental gerado por esta atividade. Desta forma, conclui-se que muitas iniciativas têm sido desenvolvidas de forma isolada.
\end{abstract}

PALAVRAS CHAVE: Resíduos de serviços de saúde; sustentabilidade; gestão

\begin{abstract}
The increase in the amount of waste from health care, coupled with the deficiency in the management of these materials has generated great concern regarding the negative impact it has on the population's health and the environment. Faced with this problem, we sought learning more about the management of waste within Health Care (Health Care's Waste management practices $=$ RSS) developed with a focus on sustainability, through a systematic review. The work allowed the survey of sustainable practices developed by several actors interested in minimizing the environmental impact generated by RSS on hospitals, both on regional and national levels. (The) Main actions involved: training, segregation, public policies, treatment technology, minimization, reuse and recycling, monitoring of RSS management, designation of an accountable individual for RSS management activities and investment by governments, amongst others. It is concluded that many initiatives have been developed in an isolated manner. The management of RSS is a complex system and to ensure all actions' success, the steps of management must be analyzed considering their particularities, however, in a complementary way towards the others. The different stakeholders must be integrated so that the sum of efforts may produce more solid and consistent results, allied with the integration between local, regional and national entities, as each link in this system is both affected by and affects the others. It was also identified the need for a more profound research that presents innovative solutions in the management of RSS and a process that allows the exchange of information between institutions and the government to scatter the best practices and accelerate the process of reducing the environmental impact generated by this activity.
\end{abstract}

KEY WORDS: hospital waste; sustainability; management 


\section{INTRODUÇÃO}

Os serviços de saúde no decorrer da história têm evoluído muito e recentemente tem incorporado inovações tecnológicas importantes. No entanto, segundo relatório da ONU (UN, 2011) a quantidade de resíduos gerados por serviços de saúde nos países em desenvolvimento está aumentando devido à expansão dos serviços de saúde, exacerbada pela falta de recursos tecnológicos e financeiros para garantir que os resíduos sejam geridos e eliminados de forma segura em prol da saúde humana e o meio ambiente.

Outros fatores têm contribuído para o aumento na geração de resíduos de serviços de saúde, como o contínuo incremento da complexidade da assistência à saúde, o uso crescente de materiais descartáveis, além do aumento da população idosa, que normalmente necessita de mais serviços de saúde, sendo usuária frequente de diversos tipos e níveis de especialidades (SISINNO; MOREIRA, 2005).

Contudo, sabe-se que cerca de 75 a $90 \%$ do total de resíduos gerados pelos serviços de saúde são comparáveis aos resíduos domésticos e não representam risco à saúde humana ou para o meio ambiente (WORLD HEALTH ORGANISATION et al., 2014). Os demais resíduos são considerados perigosos e podem criar uma variedade de riscos se não forem gerenciados e eliminados de forma adequada (UN, 2011). Por isso, é imprescindível que todos os resíduos provenientes de serviços de saúde sejam identificados, quantificados, segregados, manipulados, tratados e descartados corretamente.

A Organização Mundial de Saúde (OMS) reconhece que a segurança e sustentabilidade da gestão de resíduos resultantes dos cuidados de saúde é um imperativo na saúde pública e uma responsabilidade de todos. No entanto, em muitos países, a gestão inadequada de RSS continua a representar uma ameaça significativa, embora subestimada, aos direitos humanos, incluindo o direito à vida, o direito à saúde física e mental, o direito à segurança e saúde no trabalho e o direito a um padrão de vida adequado (UN, 2011).

De acordo com a OMS (2014) em muitos hospitais todos os resíduos são misturados e queimados em incineradores de baixa tecnologia e alto grau de poluição, produzindo dioxinas e furanos. Estes compostos são subprodutos de diversos processos industriais, os incineradores de resíduos (sólidos e de serviços de saúde) não controlados são frequentemente os maiores causadores. A distribuição destas toxinas no meio ambiente é global, são encontradas em solo, sedimentos, alimentos, especialmente laticínios, carnes, peixes e crustáceos (WHO, 2016).
Os impactos na saúde provocado pela exposição direta e indireta destas substâncias incluem efeitos carcinogênicos, danos no sistema cardiovascular, efeitos respiratórios, efeitos do sistema imunológico, má formação de fetos, entre muitos outros (BIANCO et al., 2010). Embora progressos tenham sido feitos em cuidados com o RSS, práticas de gerenciamento ainda necessitam de modificações e meIhorias. Alguns dos problemas mais comuns identificados são a gestão inadequada de resíduos, falta de consciência sobre os riscos para a saúde e a poluição ambiental, recursos financeiros e humanos insuficientes e condições inadequadas de eliminação de resíduos (MATO; KASEVA, 1999).

Diante disso, foi observada a necessidade de investigar as práticas do sistema de gestão de RSS desenvolvidas com foco na sustentabilidade e identificar lacunas existentes na literatura para oferecer suporte ao desenvolvimento de uma pesquisa que permita o maior desenvolvimento em áreas pouco exploradas.

\section{REVISÃO SISTEMÁTICA}

A revisão sistemática da literatura é um método que permite maximizar o potencial de uma busca, encontrando o maior número possível de resultados de uma maneira organizada. O seu resultado não é uma simples relação cronológica ou uma exposição linear e descritiva de uma temática construída por um trabalho reflexivo, crítico e compreensivo a respeito do material analisado (FERNÁNDEZ-RíOS; BUELA-CASAL, 2009). A revisão sistemática desta pesquisa baseou-se conceitualmente nos trabalhos desenvolvidos por Mattioda et al. (2015), Szejka et al. (2017), Teixeira e Canciglieri Junior (2019) e Uemura Reche et al. (2019). Então, para identificar as práticas de gerenciamento de RSS com foco na sustentabilidade ambiental, utilizou-se estas abordagens e na sequência, foi analisado todo o conteúdo encontrado, conforme as etapas descritas na tabela 1 .

\begin{tabular}{|l|l|l|}
\hline \multicolumn{3}{|l|}{ Quantidade de artigos selecionados por etapa } \\
\hline $1^{\text {a } e t a p a ~}$ & Busca Capes por palavras-chave & 2207 \\
\hline $2^{\text {a } e t a p a ~}$ & $\begin{array}{l}\text { Leitura do título } \\
\text { Aplicação critérios de inclusão/exclusão }\end{array}$ & 282 \\
\hline $3^{\text {a etapa }}$ & $\begin{array}{l}\text { Leitura Resumo } \\
\text { Inclusão de perguta norteadora }\end{array}$ & 93 \\
\hline $\begin{array}{l}\text { Análise de } \\
\text { conteúdo }\end{array}$ & Leitura completa & 37 \\
\hline
\end{tabular}

Tabela 01: Revisão Sistemática e Análise de Conteúdo Fonte: Autores

A revisão sistemática foi realizada por meio do sistema de base de dados científica brasileira (Periódicos CAPES) disponibilizado pela Coordenação de Aperfeiçoamento 
de Pessoal de Nível Superior (CAPES 2017) que contém aproximadamente 530 bases de dados, incluindo Cambridge Journals Online, Emerald Insight (Emerald), IEEE Xplore, Scopus (Elsevier), Science Direct, SpringerLink, Taylor e Francis entre outros. Esse sistema permite uma busca e filtragem robusta de artigos através dos parâmetros de pesquisa. Na pesquisa foram considerados para análise artigos no idioma inglês, revisados por pares, no período de 2001 até outubro de 2020.

\subsection{Determinação das palavras-chave (Primeira Etapa)}

Nesta etapa foram definidas as palavras-chave utilizadas na busca, obtidas a partir da análise exploratória onde foram selecionadas pesquisas reconhecidas como relevantes devido ao número de citações. A partir disso, observou-se o relacionamento entre três campos de pesquisa: gestão, resíduo de serviços de saúde e sustentabilidade que foram combinados da seguinte forma: "Infectious medical" OR "Infectious waste" OR "Clinical solid waste" OR "Hospital waste" OR "Health care waste" OR "Biomedical waste" AND "Sustainability" OR "Sustainable" AND "Management" OR "Maturity Model", resultando em 2.249 artigos, que após a exclusão dos artigos duplicados restaram 2.207.

\subsection{Análise de títulos e resumos dos artigos sele-} cionados (Segunda Etapa - critérios de exclusão)

Esta fase consistiu no refinamento da busca para eliminar os artigos que não faziam parte do escopo da pesquisa, utilizado como critério de exclusão: saúde ocupacional; categorias profissionais; tratamento de efluentes, resíduo doméstico e radioativo; resíduos de serviços especializados (hemodiálise, vacina, anestesia, drogas específicas, cirurgia, laboratórios, odontologia, controle de infecção, farmácia, hemoterapia, lavanderia hospitalar, nutrição, atenção primária, indústria); nível educacional da população; métodos de mensuração, estudos comparativos entre saúde pública e privada e caracterização de resíduos; capacitação de profissionais; assistência humanitária; doenças transmitidas por vetores; materiais específicos como alumínio, baterias, mercúrio e resíduos eletrônicos. Após este processo restaram 282 artigos para a próxima etapa.

\subsection{Inclusão da pergunta norteadora (Terceira Etapa - Critério de inclusão)}

Para o refinamento dos artigos foi realizada uma nova leitura para seleção dos trabalhos com abordagem sob o aspecto da sustentabilidade, para isso foi utilizada seguinte pergunta norteadora: "O artigo contribui para o desenvolvimento ambientalmente sustentável da gestão de resíduos de serviços de saúde com ações concretas?". Numa primeira leitura dos resumos e títulos remanesceram somente 93 trabalhos que eram aderentes ao tema abordado. Após a leitura completa com profundidade, resultaram somente 37 artigos que estavam alinhados com esse critério e o tema de pesquisa, como descrito em detalhes na tabela 02 .

\begin{tabular}{|c|c|c|c|c|c|}
\hline AUTOR & TÍTULO & ANO & TEMA & CONTRIBUIÇÃO & LIMITAÇÃO \\
\hline $\begin{array}{l}\text { Rume, T.; } \\
\text { Islam, S. M.D. }\end{array}$ & $\begin{array}{l}\text { Environmental } \\
\text { effects of } \\
\text { COVID-19 } \\
\text { pandemic } \\
\text { and potential } \\
\text { strategies of } \\
\text { sustainability }\end{array}$ & 2020 & $\begin{array}{l}\text { Fatores que } \\
\text { contribuem } \\
\text { para gestão } \\
\text { inadequada }\end{array}$ & $\begin{array}{l}\text { Estudo aponta que a situação de pandemia melhora significativa- } \\
\text { mente a qualidade do ar em diferentes cidades em todo o mundo, } \\
\text { reduz a emissão de GEEs, diminui a poluição da água e o ruído, e } \\
\text { reduz a pressão sobre os destinos turísticos, por outro lado há tam- } \\
\text { bém algumas consequências negativas como aumento de resíduo } \\
\text { hospitalar, uso e descarte aleatório de desinfetantes, máscara e lu- } \\
\text { vas; e aumento da carga de resíduos não tratados continuamente } \\
\text { colocando em risco o meio ambiente. } \\
\text { O aumento do uso de equipamentos de proteção e segurança e o } \\
\text { descarte aleatório aumentam a quantidade de resíduos de saúde. } \\
\text { No entanto, devido à falta de conhecimento sobre resíduos infec- } \\
\text { ciosos, a maioria das pessoas os joga em locais abertos ou com re- } \\
\text { síduos domésticos. Esse descarte desordenado cria entupimento } \\
\text { nos sistemas de esgoto e contribui para a poluição ambiental. }\end{array}$ & $\begin{array}{l}\text { Limitado ao } \\
\text { levantamento } \\
\text { de problemas } \\
\text { acentuados } \\
\text { pela pandemia } \\
\text { e não apresenta } \\
\text { soluções. }\end{array}$ \\
\hline $\begin{array}{l}\text { Sarkodie, } \\
\text { S. A.; } \\
\text { Owusu, P. A. }\end{array}$ & $\begin{array}{l}\text { Impact of } \\
\text { COVID-19 } \\
\text { pandemic } \\
\text { on waste } \\
\text { management }\end{array}$ & 2020 & $\begin{array}{l}\text { Substituição } \\
\text { do PVC } \\
\text { Pesquisa: con- } \\
\text { sequências } \\
\text { do progresso } \\
\text { tecnológico }\end{array}$ & $\begin{array}{l}\text { Artigo avaliou o impacto da COVID-19 na gestão de resíduos, obser- } \\
\text { vando medidas de bloqueio e distanciamento social.Descobriram que } \\
\text { a quantidade de resíduos aumentou entre os países que mantiveram } \\
\text { o distanciamento social. O aumento do uso de produtos de uso único } \\
\text { provocou o acúmulo destes materiais. Em Hong Kong, as máscaras } \\
\text { faciais se acumularam em trilhas naturais e praias devido ao descarte } \\
\text { inadequado em cursos d'água. Além disso, uma proibição temporária } \\
\text { de movimentos transfronteiriços afeta os países em desenvolvimento } \\
\text { que dependem de tecnologia estrangeira para atividades de recicla- } \\
\text { gem de resíduos fazendo com que a maioria dos resíduos gerados } \\
\text { durante a pandemia seja descartada em vez de reciclada. }\end{array}$ & \\
\hline
\end{tabular}




\begin{tabular}{|c|c|c|c|c|c|}
\hline & & & & $\begin{array}{l}\text { (CONTINUAÇÃO) } \\
\text { A pandemia global levou a uma quantidade incomum de resíduo } \\
\text { hospitalar relatado. Devido à adoção global de equipamentos de } \\
\text { proteção pessoal, pesquisas futuras devem ter como objetivo o } \\
\text { desenvolvimento equipamentos de proteção ecologicamente } \\
\text { corretos, incluindo máscaras faciais, luvas, macacões, entre outros, } \\
\text { para acelerar a agenda para alcançar uma produção sustentável e } \\
\text { redução dos custos ambientais. }\end{array}$ & \\
\hline $\begin{array}{l}\text { Ahmad, R.; } \\
\text { Liu, G.; } \\
\text { Santagata, } \\
\text { R.; } \\
\text { Casazza, M.; } \\
\text { Xue, J.; } \\
\text { Khan, K.; } \\
\text { Nawab, J.; } \\
\text { Ulgiati, S.; } \\
\text { Lega, M. }\end{array}$ & $\begin{array}{l}\text { LCA of hospi- } \\
\text { tal solid waste } \\
\text { treatment } \\
\text { alternatives in } \\
\text { a developing } \\
\text { country: The } \\
\text { case of District } \\
\text { Swat, Pakistan }\end{array}$ & 2019 & $\begin{array}{l}\text { Tecnologia de } \\
\text { tratamento }\end{array}$ & $\begin{array}{l}\text { O estudo avaliou os impactos ambientais das práticas de gestão } \\
\text { de resíduos hospitalares em Swath District, Paquistão. Realizou-se } \\
\text { uma avaliação do ciclo de vida para a estimativa de diferentes im- } \\
\text { pactos das práticas atuais e alternativas de tratamento de resíduos } \\
\text { sólidos hospitalares. Utilizaram-se três cenários para descrever as } \\
\text { práticas alternativas atuais (Cenário A e Cenário B), referindo-se à } \\
\text { incineração ou aterro direto do resíduo sem qualquer triagem dos } \\
\text { materiais coletados e o cenário C, que inclui o uso de pirólise e de- } \\
\text { sinfecção química. Consideraram-se oito impactos nas categorias: } \\
\text { toxicidade humana, eco-toxicidade de água doce, eco-toxicidade } \\
\text { marinha aquática, eco-toxicidade terrestre, potencial de acidifica- } \\
\text { ção, alterações climáticas, eutrofização e oxidação fotoquímica. } \\
\text { As práticas (Cenário A e Cenário B) foram as piores para todas as ca- } \\
\text { tegorias, o maior impacto de todos é registrado para a toxicidade } \\
\text { humana gerada pela incineração. }\end{array}$ & $\begin{array}{l}\text { Deve ser con- } \\
\text { siderado que } \\
\text { atualmente não } \\
\text { são implemen- } \\
\text { tadas práticas } \\
\text { de reciclagem } \\
\text { ou reutilização. }\end{array}$ \\
\hline $\begin{array}{l}\text { Ferronato, } \\
\text { N.; } \\
\text { Ragazzi, M.; } \\
\text { Elias, M.S. T.; } \\
\text { Portillo, } \\
\text { M. A. G.; } \\
\text { Lizarazu, } \\
\text { E.G.G.; } \\
\text { Torretta, V. }\end{array}$ & $\begin{array}{l}\text { Application } \\
\text { of health- } \\
\text { care waste } \\
\text { indicators for } \\
\text { assessing in- } \\
\text { fectious waste } \\
\text { management } \\
\text { in Bolivia }\end{array}$ & 2020 & $\begin{array}{l}\text { Diretrizes } \\
\text { para classi- } \\
\text { ficação das } \\
\text { instituições }\end{array}$ & $\begin{array}{l}\text { O artigo apresenta um conjunto de indicadores para avaliar a ges- } \\
\text { tão de resíduos de saúde em cidades em desenvolvimento. Os cri- } \\
\text { térios considerados foram divididos em cinco indicadores: coleta } \\
\text { e coleta seletiva; armazenamento; tratamento local; manutenção } \\
\text { e monitoramento; e Conscientização, segurança e prevenção. O } \\
\text { objetivo foi sugerir uma ferramenta de gestão integrada como } \\
\text { uma primeira técnica de avaliação para identificar os problemas } \\
\text { prevalentes no sistema de gestão de resíduos de saúde. O método } \\
\text { pode ser replicado em outros contextos em todo o mundo, princi- } \\
\text { palmente em países em desenvolvimento, para comparar cidades, } \\
\text { soluções de gestão e melhorias realizadas ao longo dos anos. } \\
\text { Os indicadores podem ser usados para comparar hospitais, fornecen- } \\
\text { do uma referência em relação ao nível de renda, características am- } \\
\text { bientais e comportamento social, podendo ser uma ferramenta para } \\
\text { contribuir para a melhoria da consciência sobre os problemas de ges- } \\
\text { tão de resíduos de serviços de saúde e os requisitos de gerenciamento } \\
\text { para impulsionar a sustentabilidade e a saúde em nível global. }\end{array}$ & \\
\hline $\begin{array}{l}\text { Di Nola, M.F.; } \\
\text { Escapa, M.; } \\
\text { Ansah, J P. }\end{array}$ & $\begin{array}{l}\text { Modelling } \\
\text { solid waste } \\
\text { management } \\
\text { solutions: } \\
\text { The case of } \\
\text { Campania, } \\
\text { Italy }\end{array}$ & 2018 & $\begin{array}{l}\text { Modelo } \\
\text { para futuras } \\
\text { melhorias na } \\
\text { infraestrutura }\end{array}$ & $\begin{array}{l}\text { É proposta uma ferramenta para desenvolver um laboratório para } \\
\text { testar futuras melhorias quanto à política de resíduos. O modelo foi } \\
\text { usado para explorar o provável impacto de alternativas políticas de } \\
\text { gestão de resíduos em diferentes níveis institucionais. Os resultados } \\
\text { apontam que as políticas de gestão que se concentram em impul- } \\
\text { sionar a segregação dos resíduos são susceptíveis a ser mais susten- } \\
\text { táveis, minimizando o aumento da capacidade da infraestrutura. }\end{array}$ & $\begin{array}{l}\text { Limitado a uma } \\
\text { proposta de } \\
\text { políticas públi- } \\
\text { cas para gestão } \\
\text { de RSS em } \\
\text { nível regional. }\end{array}$ \\
\hline $\begin{array}{l}\text { Su, E. C.; } \\
\text { Chen, Y. }\end{array}$ & $\begin{array}{l}\text { Policy or inco- } \\
\text { me to affect the } \\
\text { generation of } \\
\text { medical was- } \\
\text { tes: An applica- } \\
\text { tion of environ- } \\
\text { mental Kuznets } \\
\text { curve by using } \\
\text { Taiwan as an } \\
\text { example }\end{array}$ & 2018 & $\begin{array}{l}\text { Geração de } \\
\text { RSS e renda }\end{array}$ & $\begin{array}{l}\text { O estudo enfatiza o efeito da renda, a geração de resíduos de servi- } \\
\text { ços de saúde e o descarte ilegal por meio de associações. Apresenta } \\
\text { a relação positiva entre a geração de resíduos de serviços de saúde } \\
\text { e a receita, explicadas pelo aumento da preocupação com a saúde } \\
\text { ocasionada pelo aumento da renda. Sugere ainda que para evitar } \\
\text { o aumento contínuo na geração é necessário reduzir a demanda } \\
\text { por assistência médica e por fim considera a adoção de um sistema } \\
\text { público de monitoramento como uma abordagem para reduzir o } \\
\text { descarte ilegal de resíduos de serviços de saúde. }\end{array}$ & $\begin{array}{l}\text { Os dados usa- } \\
\text { dos na pesquisa } \\
\text { são do banco } \\
\text { de dados do go- } \\
\text { verno com base } \\
\text { na perspectiva } \\
\text { macroscópica. } \\
\text { Não podendo } \\
\text { ser aplicados no } \\
\text { nível hospitalar. }\end{array}$ \\
\hline $\begin{array}{l}\text { Ali, M.; } \\
\text { Geng, Y. }\end{array}$ & $\begin{array}{l}\text { Accounting } \\
\text { embodied } \\
\text { economic po- } \\
\text { tential of heal- } \\
\text { thcare waste } \\
\text { recycling-a } \\
\text { case study } \\
\text { from Pakistan }\end{array}$ & 2018 & $\begin{array}{l}\text { Minimização, } \\
\text { reutilização e } \\
\text { Reciclagem }\end{array}$ & $\begin{array}{l}\text { Foi utilizada a análise Emergy para avaliar o verdadeiro potencial } \\
\text { econômico da reciclagem. Foi comparado o potencial das práticas } \\
\text { atuais de reciclagem de resíduos com o cenário de } 100 \% \text { de reci- } \\
\text { clagem das frações úteis dos resíduos. Concluiu-se que a energia } \\
\text { latente incorporada de diferentes frações de resíduos recicláveis } \\
\text { os tornava mais valioso do que indicam os preços de mercado exis- } \\
\text { tentes. Este valor aumentava ainda mais se as frações de resíduos } \\
\text { úteis fossem totalmente recicladas. }\end{array}$ & $\begin{array}{l}\text { Não contabili- } \\
\text { zada as varia- } \\
\text { ções sazonais e } \\
\text { a falta de dados } \\
\text { sobre a recicla- } \\
\text { gem adequada } \\
\text { de resíduos } \\
\text { como compos- } \\
\text { tagem, incine- } \\
\text { ração e recicla- } \\
\text { gem de material } \\
\text { controlado. }\end{array}$ \\
\hline
\end{tabular}




\begin{tabular}{|c|c|c|c|c|c|}
\hline $\begin{array}{l}\text { Migdadi, } \\
\text { Y.K.A. A.; } \\
\text { Omari, A.A. }\end{array}$ & $\begin{array}{l}\text { Identifying the } \\
\text { best practices } \\
\text { in green ope- } \\
\text { rations strate- } \\
\text { gy of hospitals }\end{array}$ & 2018 & $\begin{array}{l}\text { Minimização, } \\
\text { reutilização e } \\
\text { Reciclagem }\end{array}$ & $\begin{array}{l}\text { Foram estudados } 25 \text { relatórios anuais de sustentabilidade através } \\
\text { do benchmarking e da análise quantitativa de conteúdo de relató- } \\
\text { rios de sustentabilidade. As ações foram classificadas nas catego- } \\
\text { rias gerais: redução no consumo de: papel, combustível, energia } \\
\text { elétrica, redução dos resíduos perigosos enão perigosos e redução } \\
\text { das emissões diretas de GEE (gases de efeito estufa). } \\
\text { O indicador de redução de resíduos perigosos foi considerado } \\
\text { significativo e a ação mais frequentemente tomada foi aumentar } \\
\text { a conscientização dos profissionais sobre como os resíduos devem } \\
\text { ser devidamente classificados. }\end{array}$ & \\
\hline $\begin{array}{l}\text { Awodele, O.; } \\
\text { Adewoye, } \\
\text { A. A.; } \\
\text { Oparah, A. C. }\end{array}$ & $\begin{array}{l}\text { Assessment of } \\
\text { medical waste } \\
\text { management } \\
\text { in seven } \\
\text { hospitals in } \\
\text { Lagos, Nigeria. } \\
\text { (Report) }\end{array}$ & 2016 & $\begin{array}{l}\text { Capacitação } \\
\text { Política } \\
\text { de RSS }\end{array}$ & $\begin{array}{l}\text { Avaliada as práticas de gerenciamento de resíduos e avaliado o im- } \\
\text { pacto da intervenção da Autoridade de Gestão de Resíduos. } \\
\text { O trabalho analisou o as práticas de gerenciamento em sete hospi- } \\
\text { tais e o resultado demonstrou que há pouco progresso na gestão } \\
\text { de resíduos hospitalares no estado de Lagos. As práticas de gestão } \\
\text { de resíduos entre os vários hospitais pesquisados são semelhantes, } \\
\text { exceto uma instituição que ainda mistura seus resíduos perigosos e } \\
\text { comuns. O resíduo hospitalar é coletado e segregado usando o sis- } \\
\text { tema de codificação de três cores da OMS, a seguir transferido para } \\
\text { o armazenamento local e finalmente transportado pelo Estado de } \\
\text { Lagos para a estação de carregamento de transferência onde é } \\
\text { tratado por meio de hidroclave. Este sistema é congruente com as } \\
\text { especificações da OMS; porém não há uniformidade nas práticas } \\
\text { de gestão de resíduos. Outra recomendação é o treinamento con- } \\
\text { tínuo da equipe dos hospitais em gestão de resíduos. Há também } \\
\text { a necessidade de conscientizar o paciente e a comunidade sobre o } \\
\text { sistema de gerenciamento de resíduos, a fim de prevenir infecções } \\
\text { e riscos ambientais. Acrescentam ainda que diretrizes de política e } \\
\text { regulamentação devem ser fornecidas aos três níveis de governo } \\
\text { (governo federal, estadual e local) de modo a melhorar as práticas } \\
\text { de gestão de resíduos em todo o país. }\end{array}$ & $\begin{array}{l}\text { Não apresentou } \\
\text { as diretrizes e } \\
\text { políticas para } \\
\text { gestão de RSS. }\end{array}$ \\
\hline $\begin{array}{l}\text { Caniato, M.; } \\
\text { Tudor, T.; } \\
\text { Vaccari, M. }\end{array}$ & $\begin{array}{l}\text { International } \\
\text { governance } \\
\text { structures for } \\
\text { healthcare } \\
\text { waste mana- } \\
\text { gement: A sys- } \\
\text { tematic review } \\
\text { of scientific } \\
\text { literature }\end{array}$ & 2015 & $\begin{array}{l}\text { Capacitação } \\
\text { Compartilha- } \\
\text { mento das } \\
\text { melhores } \\
\text { práticas } \\
\text { Envolvimento } \\
\text { dos gestores } \\
\text { Tecnologia de } \\
\text { tratamento } \\
\end{array}$ & $\begin{array}{l}\text { Revisado sistematicamente a literatura científica dos últimos } 15 \\
\text { anos e identificado as principais práticas e desafios, bem como } \\
\text { áreas potenciais para melhoria com o desenvolvimento de tecno- } \\
\text { logias inovadoras para processos mais simples e eficazes de segre- } \\
\text { gação, esterilização e reuso. }\end{array}$ & $\begin{array}{l}\text { Estudo limitado } \\
\text { à fase de se- } \\
\text { gregação e aos } \\
\text { procedimentos } \\
\text { de esteriliza- } \\
\text { ção e reuso. }\end{array}$ \\
\hline $\begin{array}{l}\text { Windfeld, } \\
\text { E.S.; } \\
\text { Brooks, M. S. }\end{array}$ & $\begin{array}{l}\text { Medical waste } \\
\text { management, } \\
\text { A review }\end{array}$ & 2015 & $\begin{array}{l}\text { Capacitação } \\
\text { Segregação }\end{array}$ & $\begin{array}{l}\text { Constatou-se que a melhor maneira de controlar o impacto do } \\
\text { resíduo hospitalar é produzir menos, e uma das maneiras mais } \\
\text { eficazes de fazer isso é garantir que apenas resíduos infecciosos } \\
\text { sejam enviados para tratamento e outros resíduos hospitalares } \\
\text { devem ser tratados da mesma forma que o resíduo doméstico. A } \\
\text { divisão do resíduo hospitalar apenas em infectante e comum gera } \\
\text { desperdício no aspecto ambiental que deixa de utilizar o potencial } \\
\text { de reciclagem da maioria dos resíduos gerados e no aspecto eco- } \\
\text { nômico já que aumenta consideravelmente o volume de resíduo } \\
\text { infectante onerando os custos da instituição. }\end{array}$ & \\
\hline $\begin{array}{l}\text { Caniato, M.; } \\
\text { Vaccari, M.; } \\
\text { Visvanathan, } \\
\text { C.; } \\
\text { Zurbrvogg, } \\
\text { C. }\end{array}$ & $\begin{array}{l}\text { Using social } \\
\text { network and } \\
\text { stakeholder } \\
\text { analysis to } \\
\text { help evaluate } \\
\text { infectious } \\
\text { waste mana- } \\
\text { gement: A } \\
\text { step towards } \\
\text { a holistic } \\
\text { assessment } \\
\end{array}$ & 2014 & Segregação & $\begin{array}{l}\text { Análise sobre instalação de incineração em Bangkok e a relação } \\
\text { com as partes interessadas. Sugere que a comunicação pode ser } \\
\text { melhorada e as partes interessadas podem estar estrategicamente } \\
\text { mais envolvidas. }\end{array}$ & $\begin{array}{l}\text { Limitado a um } \\
\text { método de } \\
\text { tratamento } \\
\text { de resíduos } \\
\text { considerado } \\
\text { altamente } \\
\text { poluente. }\end{array}$ \\
\hline $\begin{array}{l}\text { Alves, S.B.; } \\
\text { Souza, A.C.S.; } \\
\text { Tipple, A. F. } \\
\text { V.; Rezende, } \\
\text { K.C.; } \\
\text { Resende, F.R.; } \\
\text { Rodrigues, } \\
\text { E.G.; Pereira, } \\
\text { M. }\end{array}$ & $\begin{array}{l}\text { The reality } \\
\text { of waste } \\
\text { management } \\
\text { in primary } \\
\text { health care } \\
\text { units in Brazil }\end{array}$ & 2014 & $\begin{array}{l}\text { Fatores que } \\
\text { contribuem } \\
\text { para gestão } \\
\text { inadequada }\end{array}$ & $\begin{array}{l}\text { Estudo brasileiro em resíduos de saúde na atenção básica mostrou } \\
\text { que a maioria dos resíduos gerados é comum e reciclável. }\end{array}$ & $\begin{array}{l}\text { Limitado } \\
\text { aos resíduos } \\
\text { provenientes } \\
\text { da atenção bá- } \\
\text { sica em saúde, } \\
\text { especialmente } \\
\text { os gerados em } \\
\text { domicílio. }\end{array}$ \\
\hline
\end{tabular}




\begin{tabular}{|c|c|c|c|c|c|}
\hline $\begin{array}{l}\text { Debere, } \\
\text { M. K.; } \\
\text { Gelaye, K. A; } \\
\text { Alamdo, A., } \\
\text { G.; Trifa, } \\
\text { Z. M. }\end{array}$ & $\begin{array}{l}\text { Assessment of } \\
\text { the health care } \\
\text { waste genera- } \\
\text { tion rates and } \\
\text { its manage- } \\
\text { ment system } \\
\text { in hospitals of } \\
\text { Addis Ababa, } \\
\text { Ethiopia, }\end{array}$ & 2013 & $\begin{array}{l}\text { Tecnologia de } \\
\text { tratamento }\end{array}$ & $\begin{array}{l}\text { Apresenta o mecanismo de descarte de resíduos hospitalares em } \\
\text { Addis Abada na Etiópia sendo o principal a incineração. } \\
\text { Constatou-se que os incineradores não estavam equipados com } \\
\text { entradas de ar, e por isso colocava em risco a saúde das pessoas } \\
\text { que moram e trabalham nas proximidades. } \\
\text { O trabalho sugere que o uso de outras formas de tratamento de } \\
\text { resíduos, alternativo à incineração, como uma autoclave fabrica- } \\
\text { da localmente e integrada a um triturador, devem ser avaliadas e } \\
\text { implementadas. }\end{array}$ & $\begin{array}{l}\text { Estudo investi- } \\
\text { gativo limitado } \\
\text { a práticas de } \\
\text { tratamento } \\
\text { em hospitais } \\
\text { da Etiópia. }\end{array}$ \\
\hline $\begin{array}{l}\text { Hossain, } \\
\text { M.S.; } \\
\text { Santhanam, } \\
\text { A.; } \\
\text { Norulaini, } \\
\text { N.A.N.; } \\
\text { Omar, A. } \\
\text { K.M. }\end{array}$ & $\begin{array}{l}\text { Clinical } \\
\text { solid waste } \\
\text { management } \\
\text { practices and } \\
\text { its impact } \\
\text { on human } \\
\text { health and } \\
\text { environment } \\
\text { - A review }\end{array}$ & 2011 & $\begin{array}{l}\text { Fatores que } \\
\text { contribuem } \\
\text { para gestão } \\
\text { inadequada }\end{array}$ & $\begin{array}{l}\text { Nesta revisão, as práticas existentes de gerenciamento de resíduos } \\
\text { sólidos foram investigadas para determinar o manejo apropriado e } \\
\text { tecnologia para o gerenciamento de resíduos sólidos. } \\
\text { Em uma revisão identificou-se que embora medidas significati- } \\
\text { vas tenham sido tomadas em questões relacionadas ao manuseio } \\
\text { seguro e à eliminação dos resíduos de saúde, a prática de gestão } \\
\text { inadequada é evidente desde o ponto de coleta até a disposição } \\
\text { final. Na maioria dos casos, os principais motivos da má gestão são: } \\
\text { falta de legislação adequada, falta de corpo clínico especializado, } \\
\text { falta de conscientização e controle efetivo. O artigo enfatiza o pro- } \\
\text { grama de reciclagem e reutilização de materiais após esterilização } \\
\text { usando dióxido de carbono fluido supercrítico como tecnologia de } \\
\text { esterilização no ponto de coleta inicial. A ênfase está na prioridade } \\
\text { de desativar os microrganismos infecciosos. A adoção dessa tec- } \\
\text { nologia poderia reduzir a exposição a resíduos infecciosos, dimi- } \\
\text { nuir mão de obra, diminuir custos e produzir melhor conformidade } \\
\text { regulatória. }\end{array}$ & $\begin{array}{l}\text { Estudo inves- } \\
\text { tigativo com } \\
\text { foco na etapa } \\
\text { de geração e } \\
\text { segregação } \\
\text { de resíduos } \\
\text { infectantes. }\end{array}$ \\
\hline $\begin{array}{l}\text { Manga, V. E.; } \\
\text { Forton, O. T; } \\
\text { Mofor, L. A.; } \\
\text { Woodard, R. }\end{array}$ & $\begin{array}{l}\text { Health } \\
\text { care waste } \\
\text { management } \\
\text { in Cameroon: } \\
\text { A case study } \\
\text { from the } \\
\text { Southwestern } \\
\text { Region }\end{array}$ & 2011 & $\begin{array}{l}\text { Inovação e } \\
\text { desenvol- } \\
\text { vimento } \\
\text { Segregação }\end{array}$ & $\begin{array}{l}\text { O estudo estabelece que a pouca atenção dada à gestão de resí- } \\
\text { duos de serviços de saúde resulta na falta de uma abordagem inte- } \\
\text { grada para a formulação de políticas no mais alto nível de tomada } \\
\text { de decisão. }\end{array}$ & $\begin{array}{l}\text { Estudo baseou- } \\
\text {-se em cinco } \\
\text { unidades de } \\
\text { saúde em um } \\
\text { país que neces- } \\
\text { sita de regula- } \\
\text { mentação local. }\end{array}$ \\
\hline $\begin{array}{l}\text { Walkinshaw, } \\
\text { E. }\end{array}$ & $\begin{array}{l}\text { Medical waste- } \\
\text { management } \\
\text { practices vary } \\
\text { across Canada. } \\
\text { (News) }\end{array}$ & 2011 & $\begin{array}{l}\text { Autoridade } \\
\text { nacional } \\
\text { responsável } \\
\text { Legislação } \\
\text { Política } \\
\text { de RSS }\end{array}$ & $\begin{array}{l}\text { Sugere medidas para aumentar a conscientização sobre o RSS, ri- } \\
\text { goroso controle de saúde ocupacional dos trabalhadores, aloca- } \\
\text { ção de recursos necessários por parte do governo e o desenvol- } \\
\text { vimento de planos abrangentes de gestão de resíduos de saúde. }\end{array}$ & $\begin{array}{l}\text { Estudo limitado } \\
\text { às questões } \\
\text { de legislação } \\
\text { pertinentes } \\
\text { ao Canadá. }\end{array}$ \\
\hline $\begin{array}{l}\text { Abd El- } \\
\text { Salam, M. M. }\end{array}$ & $\begin{array}{l}\text { Hospital waste } \\
\text { management } \\
\text { in El-Beheira } \\
\text { Governorate, } \\
\text { Egypt }\end{array}$ & 2010 & $\begin{array}{l}\text { Fatores que } \\
\text { contribuem } \\
\text { para gestão } \\
\text { inadequada }\end{array}$ & $\begin{array}{l}\text { Em uma investigação sobre as práticas de gerenciamento de resí- } \\
\text { duos hospitalares utilizadas por oito hospitais localizados na cida- } \\
\text { de de Damanhour, é apresentado os principais fatores contribuin- } \\
\text { tes para as inadequações quanto às práticas de gestão de resíduos. }\end{array}$ & $\begin{array}{l}\text { Estudo investi- } \\
\text { gativo em ape- } \\
\text { nas } 8 \text { hospitais. }\end{array}$ \\
\hline $\begin{array}{l}\text { Askarian, M.; } \\
\text { Heidarpoor, } \\
\text { P.; } \\
\text { Assadian, O. }\end{array}$ & $\begin{array}{l}\text { A total quality } \\
\text { management } \\
\text { approach } \\
\text { to health- } \\
\text { care waste } \\
\text { management } \\
\text { in Namazi } \\
\text { Hospital, Iran }\end{array}$ & 2010 & $\begin{array}{l}\text { Fatores que } \\
\text { contribuem } \\
\text { para gestão } \\
\text { inadequada } \\
\text { Minimização, } \\
\text { reutilização e } \\
\text { Reciclagem } \\
\text { Política } \\
\text { de RSS }\end{array}$ & $\begin{array}{l}\text { Um conceito estruturado de gestão de resíduos, juntamente com } \\
\text { definições claras e treinamento de pessoal resultará na redução do } \\
\text { desperdício, levando consequentemente a uma diminuição das } \\
\text { despesas nos serviços de saúde. }\end{array}$ & $\begin{array}{l}\text { Estudo limitado } \\
\text { pelo curto } \\
\text { período de } \\
\text { observação so- } \\
\text { mente na fase } \\
\text { de segregação. }\end{array}$ \\
\hline $\begin{array}{l}\text { Insa, E.; } \\
\text { Zamorano, } \\
\text { M.; } \\
\text { Lopez, R. }\end{array}$ & $\begin{array}{l}\text { Critical review } \\
\text { of medical } \\
\text { waste legisla- } \\
\text { tion in Spain }\end{array}$ & 2010 & $\begin{array}{l}\text { Minimização, } \\
\text { reutilização e } \\
\text { Reciclagem } \\
\text { Política } \\
\text { de RSS } \\
\text { Segregação } \\
\text { Tecnologia de } \\
\text { tratamento }\end{array}$ & $\begin{array}{l}\text { Trata-se de uma revisão crítica da legislação espanhola sobre a } \\
\text { gestão de resíduos médicos. Compara leis regionais para identifi- } \\
\text { car semelhanças e diferenças entre elas. }\end{array}$ & $\begin{array}{l}\text { Estudo limitado } \\
\text { a legislação es- } \\
\text { panhola sobre } \\
\text { gestão de RSS. }\end{array}$ \\
\hline
\end{tabular}




\begin{tabular}{|c|c|c|c|c|c|}
\hline $\begin{array}{l}\text { Prem } \\
\text { Ananth, A.; } \\
\text { Prashanthini, } \\
\text { V.; } \\
\text { Visvanathan, } \\
\text { C. }\end{array}$ & $\begin{array}{l}\text { Healthcare } \\
\text { waste mana- } \\
\text { gement in Asia }\end{array}$ & 2010 & $\begin{array}{l}\text { Instalação de } \\
\text { reciclagem e } \\
\text { tratamento } \\
\text { Minimização, } \\
\text { reutilização e } \\
\text { Reciclagem } \\
\text { Responsável } \\
\text { designado } \\
\text { para gestão } \\
\text { de RSS } \\
\text { Segregação } \\
\text { Tecnologia de } \\
\text { tratamento } \\
\text { Transparência } \\
\text { entre institui- } \\
\text { ção de saúde } \\
\text { e governo }\end{array}$ & $\begin{array}{l}\text { Com base em um estudo de } 12 \text { países refletindo o status atual fo- } \\
\text { ram elaboradas recomendações para a gestão do RSS. As recomen- } \\
\text { dações não defendem qualquer tecnologia complexa, mas exige } \\
\text { mudanças de mentalidade de todos os interessados e identifica } 16 \\
\text { aspectos necessários para um sistema eficiente de gestão de RSS. }\end{array}$ & \\
\hline $\begin{array}{l}\text { Bendjoudi, } \\
\text { Z.; } \\
\text { Taleb, F.; } \\
\text { Abdelmalek, } \\
\text { F.; } \\
\text { Addou, A. }\end{array}$ & $\begin{array}{l}\text { Healthcare } \\
\text { waste mana- } \\
\text { gement in } \\
\text { Algeria and } \\
\text { Mostaganem } \\
\text { department }\end{array}$ & 2009 & $\begin{array}{l}\text { Responsável } \\
\text { designado } \\
\text { para gestão } \\
\text { de RSS }\end{array}$ & $\begin{array}{l}\text { Os resultados mostraram que há uma falta de estratégia de gestão } \\
\text { de resíduos de saúde, bem como a falta de responsável por geren- } \\
\text { ciar a gestão de resíduos no nível hospitalar. }\end{array}$ & $\begin{array}{l}\text { Estudo } \\
\text { investigativo } \\
\text { para retratar a } \\
\text { realidade sobre } \\
\text { a gestão de RSS } \\
\text { da Argélia. }\end{array}$ \\
\hline $\begin{array}{l}\text { Birpinar, M. } \\
\text { E.; Bilgili, } \\
\text { M. S.; } \\
\text { Erdogan, T. }\end{array}$ & $\begin{array}{l}\text { Medical waste } \\
\text { management } \\
\text { in Turkey: A } \\
\text { case study } \\
\text { of Istanbul }\end{array}$ & 2009 & $\begin{array}{l}\text { Monitora- } \\
\text { mento do } \\
\text { gerenciamen- } \\
\text { to de RSS }\end{array}$ & $\begin{array}{l}\text { Analisado o estado da gestão de resíduos hospitalares à luz do } \\
\text { Regulamento de Controle de Resíduos Médicos em Istambul, cons- } \\
\text { tatado que alguns regulamentos ainda precisam ser colocados em } \\
\text { prática. }\end{array}$ & $\begin{array}{l}\text { Estudo limitado } \\
\text { a realidade } \\
\text { de um país } \\
\text { quanto à } \\
\text { adequação aos } \\
\text { seus próprios } \\
\text { regulamentos. }\end{array}$ \\
\hline $\begin{array}{l}\text { Cheng, Y. W.; } \\
\text { Sung, F. C.; } \\
\text { Yang, Y.; } \\
\text { Lo, Y. H.; } \\
\text { Chung, Y. T.; } \\
\text { Li, K. C. }\end{array}$ & $\begin{array}{l}\text { Medical waste } \\
\text { production } \\
\text { at hospitals } \\
\text { and associa- } \\
\text { ted factors }\end{array}$ & 2009 & Segregação & $\begin{array}{l}\text { Avaliada a quantidade de resíduos de saúde gerados e os fatores } \\
\text { associados à taxa de geração. } \\
\text { O estudo sugere que grandes hospitais são a principal fonte de } \\
\text { resíduos médicos, em contrapartida são as organizações que pos- } \\
\text { suem melhor alavancagem para negociar com os coletores de re- } \\
\text { síduos recicláveis. }\end{array}$ & $\begin{array}{l}\text { Estudo limitado } \\
\text { a fase de ge- } \\
\text { ração de RSS. }\end{array}$ \\
\hline $\begin{array}{l}\text { Coker, A.; } \\
\text { Sangodoyin, } \\
\text { A.; } \\
\text { Sridhar, M.; } \\
\text { Booth, C.; } \\
\text { Olomolaiye, } \\
\text { P.; } \\
\text { Hammond, F. }\end{array}$ & $\begin{array}{l}\text { Medical waste } \\
\text { management } \\
\text { in Ibadan, } \\
\text { Nigeria: } \\
\text { Obstacles and } \\
\text { prospects }\end{array}$ & 2009 & $\begin{array}{l}\text { Capacitação } \\
\text { Mídia }\end{array}$ & $\begin{array}{l}\text { Investigado as práticas atuais relativas à geração e gestão de resí- } \\
\text { duos médicos e comparado com as melhores práticas. }\end{array}$ & $\begin{array}{l}\text { Estudo investi- } \\
\text { gativo limitado } \\
\text { a realidade de } \\
\text { uma cidade } \\
\text { na Nigéria. }\end{array}$ \\
\hline Gupta, S. & $\begin{array}{l}\text { Rules and } \\
\text { management } \\
\text { of biomedi- } \\
\text { cal waste at } \\
\text { Vivekananda } \\
\text { Polyclinic: A } \\
\text { case study }\end{array}$ & 2009 & $\begin{array}{l}\text { Capacitação } \\
\text { Comprometi- } \\
\text { mento da } \\
\text { equipe de } \\
\text { saúde e } \\
\text { gestores }\end{array}$ & $\begin{array}{l}\text { Foi analisado o sistema de gestão de resíduos biomédicos, incluin- } \\
\text { do política, prática e constatou-se conformidade com os padrões } \\
\text { estabelecidos no marco regulatório devido ao seu compromisso } \\
\text { com o meio ambiente. }\end{array}$ & $\begin{array}{l}\text { Estudo de uma } \\
\text { determinada } \\
\text { realidade e o } \\
\text { cumprimento } \\
\text { de padrões pré- } \\
\text {-estabelecidos. }\end{array}$ \\
\hline $\begin{array}{l}\text { Harhay, } \\
\text { M. O.; } \\
\text { Halpern, } \\
\text { S. D.; } \\
\text { Harhay, J. S.; } \\
\text { Olliaro, P. L. }\end{array}$ & $\begin{array}{l}\text { Health } \\
\text { care waste } \\
\text { management: } \\
\text { a neglected } \\
\text { and growing } \\
\text { public health } \\
\text { problem } \\
\text { worldwide }\end{array}$ & 2009 & $\begin{array}{l}\text { Pesquisa: con- } \\
\text { sequências } \\
\text { do progresso } \\
\text { tecnológico }\end{array}$ & $\begin{array}{l}\text { Divulgado um inventário de } 87 \text { documentos relativos a práticas de } \\
\text { gestão de resíduos de cuidados de saúde e desafios em } 40 \text { países } \\
\text { de baixa e média renda em todo o mundo, através de uma revisão } \\
\text { sistemática. }\end{array}$ & $\begin{array}{l}\text { Revisão } \\
\text { Sistemática de } \\
\text { documentos } \\
\text { que possivel- } \\
\text { mente sofreram } \\
\text { alterações após } \\
\text { a publicação. }\end{array}$ \\
\hline $\begin{array}{l}\text { Yang, C.; } \\
\text { Peijun, L.; } \\
\text { Lupi, C.; } \\
\text { Yangzhao, S.; } \\
\text { Diandou, X.; } \\
\text { Qian, F.; } \\
\text { Shasha, F. }\end{array}$ & $\begin{array}{l}\text { Sustainable } \\
\text { management } \\
\text { measures for } \\
\text { healthcare } \\
\text { waste in China }\end{array}$ & 2009 & $\begin{array}{l}\text { Investimento } \\
\text { pelos } \\
\text { governos } \\
\text { Supervisão } \\
\text { e monito- } \\
\text { ramento } \\
\text { ambiental } \\
\text { Tecnologia de } \\
\text { tratamento }\end{array}$ & $\begin{array}{l}\text { Discutidas as ações voltadas para o manejo sustentável de resídu- } \\
\text { os hospitalares, levando em consideração a atual situação e as exi- } \\
\text { gências decorrentes da Convenção de Estocolmo sobre Poluentes } \\
\text { Orgânicos Persistentes e as recomendações da OMS. }\end{array}$ & $\begin{array}{l}\text { A incineração } \\
\text { foi considera- } \\
\text { da a principal } \\
\text { alternativa de } \\
\text { tratamento } \\
\text { de resíduos } \\
\text { hospitalares. }\end{array}$ \\
\hline
\end{tabular}




\begin{tabular}{|c|c|c|c|c|c|}
\hline $\begin{array}{l}\text { Abdulla, F.; } \\
\text { Abu } \\
\text { Qdais, H.; } \\
\text { Rabi, A. }\end{array}$ & $\begin{array}{l}\text { Site inves- } \\
\text { tigation on } \\
\text { medical waste } \\
\text { management } \\
\text { practices } \\
\text { in northern } \\
\text { Jordan }\end{array}$ & 2008 & $\begin{array}{l}\text { Capacitação } \\
\text { Política } \\
\text { de RSS }\end{array}$ & $\begin{array}{l}\text { Apresenta a necessidade de uma estratégia de gestão baseada em } \\
\text { opções de gerenciamento de resíduos por etapas. }\end{array}$ & $\begin{array}{l}\text { Estudo explora- } \\
\text { tório da gestão } \\
\text { dos hospitais } \\
\text { da Jordânia. }\end{array}$ \\
\hline $\begin{array}{l}\text { Alagoez, } \\
\text { A.Z. }\end{array}$ & $\begin{array}{l}\text { Determination } \\
\text { of the best } \\
\text { appropriate } \\
\text { management } \\
\text { methods for } \\
\text { the health- } \\
\text { care wastes } \\
\text { in Istanbul }\end{array}$ & 2008 & Capacitação & $\begin{array}{l}\text { A gestão dos resíduos de cuidados de saúde em Istambul foi anali- } \\
\text { sada do ponto de vista das práticas existentes e definiu que para o } \\
\text { gerenciamento eficaz era necessário um programa de treinamento } \\
\text { e certificação para o pessoal envolvido na gestão e manipulação } \\
\text { de resíduos hospitalares. }\end{array}$ & \begin{tabular}{|l} 
Apresenta a \\
relação entre \\
programas de \\
treinamento \\
e a correta \\
segregação \\
dos resíduos \\
hospitalares \\
na realidade \\
de um país.
\end{tabular} \\
\hline $\begin{array}{l}\text { Mbongwe, } \\
\text { B.; } \\
\text { Mmereki, } \\
\text { B. T.; } \\
\text { Magashula, } \\
\text { A. }\end{array}$ & $\begin{array}{l}\text { Healthcare } \\
\text { waste ma- } \\
\text { nagement: } \\
\text { Current practi- } \\
\text { ces in selected } \\
\text { healthcare } \\
\text { facilities, } \\
\text { Botswana }\end{array}$ & 2008 & $\begin{array}{l}\text { Capacitação } \\
\text { Plano de } \\
\text { Gerencia- } \\
\text { mento } \\
\text { Responsável } \\
\text { designado } \\
\text { para gestão } \\
\text { de RSS }\end{array}$ & $\begin{array}{l}\text { Realizado uma revisão das práticas de gerenciamento de resídu- } \\
\text { os no nível hospitalar e foi constatado a necessidade de geren- } \\
\text { ciamento de resíduos hospitalares, de plano de gerenciamento e } \\
\text { funcionário especialmente designado para coordenar atividades } \\
\text { de gestão de resíduos além de treinamento. }\end{array}$ & $\begin{array}{l}\text { Limitado ao ní- } \\
\text { vel da unidade } \\
\text { de saúde em } \\
\text { um país com sé- } \\
\text { rias dificuldades } \\
\text { financeiras e } \\
\text { que não con- } \\
\text { segue seguir } \\
\text { as recomenda- } \\
\text { ções da OMS. }\end{array}$ \\
\hline Zamoner, M. & $\begin{array}{l}\text { Model for } \\
\text { evaluating } \\
\text { plans for } \\
\text { health service } \\
\text { waste manage- } \\
\text { ment (MPHSW) } \\
\text { for use by local } \\
\text { health and } \\
\text { environmental } \\
\text { protection } \\
\text { authorities }\end{array}$ & 2008 & $\begin{array}{l}\text { Monitora- } \\
\text { mento do } \\
\text { gerenciamen- } \\
\text { to de RSS }\end{array}$ & $\begin{array}{l}\text { Trata-se de um modelo para avaliação do PGRSS (Programa de } \\
\text { Gerenciamento de Resíduos de Serviços de Saúde) pelas secreta- } \\
\text { rias municipais de saúde. Esse modelo visa acompanhar a evolução } \\
\text { da qualidade dos planos de resíduos de saúde sob sua responsabi- } \\
\text { lidade, tendo um monitoramento anual eficiente. }\end{array}$ & \begin{tabular}{|l} 
Limitado a \\
avaliação de \\
implementa- \\
ção de PGRSS \\
dentro de \\
parâmetros pré- \\
-estabelecidos.
\end{tabular} \\
\hline $\begin{array}{l}\text { Soliman, } \\
\text { S. M.; } \\
\text { Ahmed, A. I. }\end{array}$ & $\begin{array}{l}\text { Overview } \\
\text { of biome- } \\
\text { dical waste } \\
\text { management } \\
\text { in selected } \\
\text { Governorates } \\
\text { in Egypt: A } \\
\text { pilot study }\end{array}$ & 2007 & $\begin{array}{l}\text { Fatores que } \\
\text { contribuem } \\
\text { para gestão } \\
\text { inadequada }\end{array}$ & $\begin{array}{l}\text { A manipulação e tratamento de resíduos biomédicos em diferen- } \\
\text { tes configurações de cuidados de saúde foram avaliados e obser- } \\
\text { varam práticas inadequadas em várias etapas do fluxo de resíduos. }\end{array}$ & $\begin{array}{l}\text { Estudo limitado } \\
\text { a realidade de } \\
\text { um país que } \\
\text { não possui po- } \\
\text { líticas escritas e } \\
\text { diretrizes claras. }\end{array}$ \\
\hline $\begin{array}{l}\text { Jang, Y.; } \\
\text { Lee, C.; } \\
\text { Yoon, O.; } \\
\text { Kim, H. }\end{array}$ & $\begin{array}{l}\text { Medical waste } \\
\text { management } \\
\text { in Korea }\end{array}$ & 2006 & $\begin{array}{l}\text { Minimização, } \\
\text { reutilização e } \\
\text { Reciclagem } \\
\text { Substituição } \\
\text { do PVC } \\
\text { Tecnologia de } \\
\text { tratamento }\end{array}$ & $\begin{array}{l}\text { Apresenta uma visão geral das práticas atuais de gerenciamento } \\
\text { de resíduos médicos na Coréia. Informações sobre geração, com- } \\
\text { posição, segregação, transporte e descarte de resíduos médicos } \\
\text { são discutidas. }\end{array}$ & $\begin{array}{l}\text { A incineração } \\
\text { é o método } \\
\text { de tratamen- } \\
\text { to preferido } \\
\text { na Coreia, } \\
\text { considerado o } \\
\text { mais poluente. }\end{array}$ \\
\hline $\begin{array}{l}\text { Woolridge, } \\
\text { A.; } \\
\text { Morrissey, A.; } \\
\text { Phillips, P. S. }\end{array}$ & $\begin{array}{l}\text { The deve- } \\
\text { lopment of } \\
\text { strategic and } \\
\text { tactical tools, } \\
\text { using systems } \\
\text { analysis, for } \\
\text { waste mana- } \\
\text { gement in } \\
\text { large complex } \\
\text { organizations: } \\
\text { a case study in } \\
\text { UK health- } \\
\text { care waste }\end{array}$ & 2005 & $\begin{array}{l}\text { Diretrizes } \\
\text { para classi- } \\
\text { ficação das } \\
\text { instituições }\end{array}$ & $\begin{array}{l}\text { Proposta duas ferramentas para oferecer melhores práticas em um } \\
\text { ambiente hospitalar. A adoção da metodologia levou a uma signi- } \\
\text { ficativa redução no custo dos resíduos. } \\
\text { A metodologia permite a adoção de um princípio orientador con- } \\
\text { sistente com a gestão sustentável de resíduos. }\end{array}$ & $\begin{array}{l}\text { Estudo de caso } \\
\text { que necessita } \\
\text { de maior amos- } \\
\text { tragem para } \\
\text { validação das } \\
\text { ferramentas. }\end{array}$ \\
\hline
\end{tabular}




\begin{tabular}{|l|l|l|l|l|l|}
\hline $\begin{array}{l}\text { Askarian, M.; } \\
\text { Vakili, M.; } \\
\text { Kabir, G. }\end{array}$ & $\begin{array}{l}\text { Results of a } \\
\text { hospital waste } \\
\text { survey in } \\
\text { private hos- } \\
\text { pitals in Fars } \\
\text { province, Iran }\end{array}$ & 2004 & $\begin{array}{l}\text { Conscien- } \\
\text { tização da } \\
\text { equipe e } \\
\text { usuários } \\
\text { Investimento } \\
\text { pelos } \\
\text { governos } \\
\text { Segregação }\end{array}$ & $\begin{array}{l}\text { Todos os resíduos gerados em alguns hospitais do Iran eram consi- } \\
\text { derados como infectantes, contrariando as diretrizes de gestão de } \\
\text { resíduos e apresenta ainda os pontos críticos que contribuem para } \\
\text { as falhas no sistema. }\end{array}$ & $\begin{array}{l}\text { Limitado } \\
\text { ao estudo } \\
\text { investigativo } \\
\text { da realidade de } \\
\text { um país há mais } \\
\text { de uma década. }\end{array}$ \\
\hline $\begin{array}{l}\text { Almuneef, } \\
\text { Memish, Z. A. }\end{array}$ & $\begin{array}{l}\text { Effective } \\
\text { medical waste } \\
\text { management: } \\
\text { It can be done }\end{array}$ & 2003 & $\begin{array}{l}\text { Capacitação } \\
\text { Monitora- } \\
\text { mento do RSS } \\
\text { Política } \\
\text { de RSS }\end{array}$ & $\begin{array}{l}\text { Incorporada uma política escrita sobre geração de resíduos que } \\
\text { demonstrou que a gestão eficaz pode reduzir custos e o risco para } \\
\text { a saúde e ainda proteger o meio ambiente. }\end{array}$ & $\begin{array}{l}\text { Resultado de política de } \\
\text { umasíduos de ser- } \\
\text { viços de saúde } \\
\text { na realidade de } \\
\text { um hospital da } \\
\text { Arábia Saudita. }\end{array}$ \\
\hline
\end{tabular}

Tabela 02 - Principais contribuições para o desenvolvimento ambientalmente sustentável na gestão de RSS.

Fonte: Autores

\section{RESULTADO}

A tabela 02 apresenta os artigos relevantes do estudo a partir da data de publicação, ordenado da mais recente a mais antiga. No estudo, foi realizada uma análise quantitativa para identificar o perfil da amostra e uma análise qualitativa descrevendo as respectivas contribuições e limitações de cada pesquisa reportada nos artigos focados no desenvolvimento ambientalmente sustentável da gestão de resíduos de serviços de saúde. Com isso, foi possível identificar as práticas sustentáveis desenvolvidas por diversos atores interessados em minimizar o impacto ambiental gerado pelos resíduos de serviços de saúde.

As Principais contribuições encontradas na literatura para o desenvolvimento ambientalmente sustentável na gestão de RSS, foram:

i) A modelagem de soluções de gestão de resíduos sólidos aplicado em uma empresa italiana;

ii) A aplicação da curva ambiental de Kuznets na política ou na receita que afetam a geração de resíduos médicos; iii) A avaliação da gestão de resíduos médicos aplicados em sete hospitais na cidade de Lagos na Nigéria; iv) Uma revisão sistemática da literatura científica abordando as estruturas de governança internacional para a gestão de resíduos de saúde nos últimos 15 anos;

v) Uma revisão sobre gestão de resíduos médicos;

vi) Análise sobre instalação de incineração em Bangkok por meio do uso de rede social e análise de partes interessadas para auxiliar na avaliação da gestão de resíduos infecciosos;

vii) Estudo brasileiro em resíduos de saúde mostrando que a maioria dos resíduos gerados é comum e reciclável;

viii) Avaliação das taxas de geração de resíduos de saúde e seu sistema de gestão em hospitais da cidade de Addis Ababa, na Etiópia; ix) Uma revisão sobre as práticas clínicas de gestão de resíduos sólidos e seu impacto na saúde humana e no meio ambiente;

x) Um estudo de caso abordando a gestão de resíduos de cuidados de saúde na região sudeste de Camarões;

xi) Um estudo sobre as práticas variadas de gestão de resíduos médicos em todo o Canadá;

xii) Estudo investigativo em 8 hospitais da região de Beheira no Egito sobre a gestão de resíduos hospitalares;

xiii) Uma abordagem de gestão de qualidade total para gestão de resíduos de saúde no Hospital na cidade de Namazi no Irã;

xiv) Uma revisão crítica da legislação sobre resíduos hospitalares na Espanha;

xv) Um estudo de gestão de resíduos de saúde em 12 países da Ásia refletindo o status atual como foram elaboradas as recomendações da gestão do RSS;

xvi) Estudo investigativo sobre gestão de resíduos de saúde na Argélia;

xvii) Um estudo de caso sobre a gestão de resíduos médicos na cidade de Istambul na Turquia;

xviii) Avaliação da quantidade de resíduos de saúde gerados e os fatores associados à taxa de geração de resíduos hospitalares;

xix) Estudo investigativo de gestão de resíduos médicos na cidade de Ibadan na Nigéria, apresentando os obstáculos e perspectivas;

$x x$ ) Estudo de uma realidade determinada e o cumprimento de padrões pré-definidos sobre as normas e gestão de resíduos biomédicos na Policlínica de Vivekananda;

xxi) Estudo sobre a gestão de resíduos de serviços de saúde abordando um problema de saúde pública 
negligenciado e crescente em todo o mundo;

xxii) Estudo sobre as medidas de gestão sustentável dos resíduos de saúde na China;

xxiii) Estudo exploratório da gestão dos hospitais da Jordânia envolvendo a investigação local sobre práticas de gerenciamento de resíduos hospitalares;

xxiv) Estudo sobre a determinação dos métodos mais adequados de gestão dos resíduos de saúde em Istambul;

xxv) Estudo sobre a gestão de resíduos de saúde abordando as práticas atuais em unidades de saúde selecionadas na Botswana;

xxvi) Modelo de avaliação de planos de gestão de resíduos de serviços de saúde (MPHSW) para uso pelas autoridades locais de saúde e proteção ambiental pelas secretarias municipais de saúde;

xxvii) Um estudo piloto sobre a visão geral da gestão de resíduos biomédicos no Egito;

xxviii) Estudo sobre a gestão de resíduos médicos na Coréia;

xxix) Um estudo de caso em resíduos de saúde no Reino Unido envolvendo o desenvolvimento de ferramentas estratégicas e táticas, usando análise de sistemas, para gestão de resíduos em grandes organizações complexas;

xxx) Análise de resultados de uma pesquisa de resíduos hospitalares em hospitais privados na província de Fars no Irã;

xxxi) Análise do resultado de gerenciamento eficaz de resíduos médicos por meio de uma política de resíduos de serviços de saúde em um hospital da Arábia Saudita.

Após leitura completa dos artigos, observou-se que alguns temas se repetiam e por isso foram agrupados para analisar com maior profundidade as principais práticas que contribuíam para a gestão ambientalmente sustentável de resíduos de serviços de saúde. Desta maneira, a partir destes dados, foi construída a tabela 3 que apresenta os temas das ações desenvolvidas e suas respectivas frequências nos artigos relevantes selecionados.

\begin{tabular}{|l|l|l|}
\hline Temas abordados & $\mathbf{n}^{\circ}$ & $\%$ \\
\hline Capacitação & 12 & 17,14 \\
\hline Segregação & 7 & 10 \\
\hline Política de RSS & 6 & 8,57 \\
\hline Tecnologia de tratamento & 7 & 10 \\
\hline Fatores contribuintes para gestão inadequada & 6 & 8,57 \\
\hline Minimização, reutilização e Reciclagem & 4 & 5,71 \\
\hline Monitoramento do gerenciamento de RSS & 3 & 4,29 \\
\hline
\end{tabular}

\begin{tabular}{|l|l|l|}
\hline $\begin{array}{l}\text { Responsável designado para gerenciar as ativida- } \\
\text { des de gestão de RSS }\end{array}$ & 3 & 4,29 \\
\hline Investimento pelos governos & 2 & 2,86 \\
\hline Autoridade nacional responsável & 1 & 1,43 \\
\hline Compartilhamento das melhores práticas & 1 & 1,43 \\
\hline $\begin{array}{l}\text { Comprometimento da equi- } \\
\text { pe de saúde e gestores }\end{array}$ & 1 & 1,43 \\
\hline Conscientização da equipe e usuários & 1 & 1,43 \\
\hline Diretrizes para classificação das instituições & 2 & 2,86 \\
\hline Envolvimento dos gestores & 1 & 1,43 \\
\hline Geração de RSS é afetado positivamente pela renda & 1 & 1,43 \\
\hline $\begin{array}{l}\text { Inovação e desenvolvimentos de } \\
\text { soluções de baixo custo }\end{array}$ & 1 & 1,43 \\
\hline Instalação completa de reciclagem e tratamento & 1 & 1,43 \\
\hline Legislação & 1 & 1,43 \\
\hline Mídia & 1 & 1,43 \\
\hline Modelo para futuras melhorias na infraestrutura & 1 & 1,43 \\
\hline $\begin{array}{l}\text { Necessidade de pesquisa e atenção para as } \\
\text { consequências do progresso tecnológico }\end{array}$ & 2 & 2,86 \\
\hline Plano de Gerenciamento & 1 & 1,43 \\
\hline Substituição do PVC & 2 & 2,86 \\
\hline Supervisão e monitoramento Ambiental & 1 & 1,43 \\
\hline $\begin{array}{l}\text { Transparência na gestão entre ins- } \\
\text { tituição de saúde e governo }\end{array}$ & 1 & 1,43 \\
\hline
\end{tabular}

Tabela 03: Frequência dos temas abordados Fonte: Autores

$\mathrm{Na}$ leitura dos artigos observa-se um contraponto em relação a forma de abordagem da gestão sustentável de resíduos de serviços de saúde. Enquanto a maioria das pesquisas abordadas nos artigos investigou práticas que auxiliam na gestão sustentável, 6 artigos abordaram os fatores que contribuíram para a gestão inadequada destes resíduos. É interessante ressaltar que os resultados desses dois grupos são convergentes quanto a indicação dos fatores chave para a garantia da sustentabilidade do sistema.

\section{DISCUSSÃO}

Além dos problemas já mencionados, observa-se que ainda a situação da pandemia de Covid-19, obedecendo as medidas protetivas de quarentena, isolamento e distanciamento social pode acarretar um aumento relevante na quantidade de resíduos. Estima-se que os resíduos sólidos domiciliares terão um aumento de 15 a 25\%, sendo que, um crescimento importante será na geração de resíduos de serviços de saúde de 10 a 20 vezes quando comparado ao período normal (ABRELPE, 2020).

Desde o agravamento do surto de COVID-19, a geração de resíduos hospitalares aumentou globalmente, o que é uma grande ameaça à saúde pública e ao meio ambiente. 
A coleta de amostra dos pacientes suspeitos de COVID-19, diagnóstico, tratamento de grande número de pacientes e limpeza e desinfecção representam uma grande percentagem dos resíduos infecciosos e biomédicos gerados em hospitais (RUME; ISLAM, 2020).

Através deste trabalho pode-se elencar as principais práticas desenvolvidas para melhoria da gestão de resíduos de serviços de saúde com foco na redução do impacto ambiental gerado por esta atividade. Para facilitar a discussão as práticas abordadas foram agrupadas por nível de abrangência: hospitalar, regional e nacional.

No nível hospitalar, a capacitação de pessoal foi a questão mais abordada nos artigos (ALMUNEEF e MEMISH, 2003; ABDULLA et al., 2008; ALAGOEZ, 2008; MBONGWE et al., 2008; COKER et al., 2009; GUPTA, 2009; CANIATO et al. 2015; WINDFELD e BROOKS, 2015; AWODELE et al., 2016). Os estudos se concentraram em identificar as necessidades de treinamento e a importância de uma equipe capacitada para gestão de resíduos de serviços de saúde desde a diretoria que precisa ter conhecimento da importância do processo até os colaboradores operacionais que precisam realizar o descarte correto dos resíduos.

Segundo Askarian et al. (2010) o treinamento de pessoal resultará na redução do desperdício, levando consequentemente a uma diminuição das despesas nas organizações de saúde, por meio da segregação no local de geração de forma correta, reduzindo assim a quantidade de resíduos infecciosos. Para Cheng et al. (2009), o ciclo de vida dos resíduos (da geração ao descarte final) e abordagens holísticas para gestão de resíduos são os critérios mais importantes para a gestão sustentável e confiável de RSS. Para isso, é imprescindível que haja soluções de controle para gestão de RSS como: introdução de um plano de gestão de resíduos que inclua educação, treinamento em serviço obrigatório, auditoria do tipo e volume de resíduos gerados por departamento e introdução de uma política escrita sobre gestão de resíduos.

A gestão eficaz pode reduzir custos e o risco para a saúde e ainda proteger o meio ambiente (ALMUNEEF; MEMISH, 2003). A negligência, em termos de gestão de resíduos de serviços de saúde, contribui significativamente para a poluição do meio ambiente, afeta a saúde dos seres humanos e esgota os recursos naturais e financeiros (GUPTA et al., 2009).

A segregação de resíduos baseada nas diretrizes da OMS foi prática abordada, relacionando esta fase como fator decisivo na quantidade de geração de resíduos infectantes, reafirmando a importância desta fase conforme apontado como a principal dificuldade encontrada no fluxo de resíduos.
Para garantir a qualidade nesta fase do gerenciamento de resíduos é recomendado a utilização do sistema de segregação baseado nas diretrizes da OMS (ANANTH et al., 2010). A classificação desnecessária de resíduos como infectantes resulta em custos mais altos de descarte e um aumento no impacto ambiental indesejável. E ainda é necessário considerar que a tendência global de aumento do uso de serviços de saúde resultará em um aumento na quantidade de resíduos (WINDFELD; BROOKS, 2015).

Quanto aos resíduos comuns existe potencial para recuperar os materiais do fluxo de resíduos desde que existam sistemas de gestão implementados. Recuperar separadamente resíduos não contaminados faz parte de um mercado secundário e ainda contribui para a eficiência dos recursos e para a conservação de recursos naturais. Isso possibilita a redução das quantidades de resíduos a serem incinerados resultando em menor potencial para poluentes orgânicos persistentes (POPs) e gases de efeito estufa a serem liberados no meio ambiente (MANGA et al., 2011).

No entanto, estudo aponta que, mesmo com sistema gestão de RSS implementados, os resíduos tratados como infecciosos são muito maiores que os recomendados pelas diretrizes vigentes deixando de utilizar o potencial de reciclagem (CHENG et al., 2009). Isto leva a correlacionar a prática de segregação de resíduos com a capacitação permanente, já que tais ações em conjunto podem potencializar o resultado esperado.

Para garantir o cumprimento das atividades de acordo com a legislação vigente há necessidade de haver um responsável especialmente designado para gerenciar as atividades de gestão de RSS.

Um sistema adequado deve possuir um quadro exclusivo para os profissionais de saúde, papéis e responsabilidades claramente definidos e ainda um sistema para garantir responsabilidade e transparência em gestão de RSS entre instituição de saúde e governo (ANANTH et al., 2010).

Porém, estudo mostra que há uma carência de estratégia de gestão de resíduos de saúde, bem como a falta de membro da equipe responsável por gerenciar e coordenar a gestão de resíduos no nível hospitalar (BENDJOUDI et al., 2009).

Outra prática recomendada e considerada o maior desafio no futuro é a minimização e reciclagem de resíduos. Segundo a Organização Mundial da Saúde (2014), até $90 \%$ dos resíduos de serviços de saúde não são perigosos, desde que adequadamente separados, podendo ser minimizados através da reutilização e reciclagem resultando na diminuição da quantidade de resíduo a ser tratado. Sugere ainda a utilização de métodos alternativos de tratamento (JANG et al., 2006). 
Para Almuneef e Memish (2003), a auditoria do tipo e volume de resíduos gerados por departamento pode ser uma das soluções de controle para gestão de RSS, pois segundo Crepaldi (2010) trata-se de uma ferramenta importante para garantir a aplicação das normas de forma eficiente.

Outro estudo recomenda maior compartilhamento das melhores práticas desenvolvidas e provisão de apoio para permitir uma governança mais efetiva. Esse suporte e compartilhamento não precisam necessariamente vir de países "desenvolvidos", mas sim através de agrupamentos regionais (CANIATO et al., 2014).

O compartilhamento de melhores práticas possibilita a identificação de práticas de sucesso, fortalecendo as redes de relacionamento e estimulado uma cultura da troca de informações.

No nível local o maior desafio apontado é o tratamento de resíduos de serviços saúde, os artigos apontaram este tema como alto potencial de impacto ambiental, agravado ainda pelas questões levantadas anteriormente como a dificuldade de separar o resíduo infectante do resíduo comum.

Estudo detectou as diferenças em relação aos critérios utilizados para triagem, coleta, armazenamento, transporte, tratamento e práticas de disposição e concluiu que essas diferenças podem ter implicações na saúde, bem como consequências ambientais e econômicas, tanto dentro como fora das instalações de saúde. Diante disso, é proposto um conjunto de critérios gerais sobre os quais a gestão de resíduos de saúde deve ser baseada, dentre elas a implementação de tecnologias de tratamento de resíduos que respeitem o meio ambiente (INSA et al., 2010).

Estudo propõe a utilização de um instrumento muito interessante que permite a adoção de um princípio orientador consistente com a gestão sustentável de resíduos e diretrizes para gestão sustentável de resíduos nos domínios: i) administração; ii) questões sociais; iii) saúde e segurança; iv) uso de energia e água; v) compra e fornecimento; vi) gestão de resíduos (responsabilidade, segregação, armazenamento e embalagem); vii) transporte de resíduos; viii) Reciclagem; ix) tratamento de resíduos; e x) disposição final. Essas diretrizes classificam a instituição de saúde de nível 0 - insustentável até o nível 4 - sustentável (WOOLRIDGE et al., 2005).

Outra ferramenta que pode auxiliar no gerenciamento de RSS, é um modelo desenvolvido por Zamoner (2008) que permite a avaliação da adequação da gestão de resíduos de uma instituição hospitalar com as normas vigentes, possibilitando acompanhar sua evolução anual. Artigo sugere que abordagens holísticas, como supervisão e monitoramento ambiental, é um dos critérios mais importantes para a gestão sustentável e confiável de RSS (YANG et al., 2009). Utilizar a mídia de massa pode ajudar a sensibilizar a população elevando seu nível de conscientização sobre os riscos ambientais associados ao manejo inadequado do resíduo hospitalar (Coker et al., 2009).

A divulgação de informações corretas é importante, como o fato de que nem todo resíduo hospitalar é infectante, e pode aumentar a conscientização pública quanto a responsabilidade de todos (ASKARIAN et al., 2010).

Em nível nacional a prática mais abordada está relacionada à Política de RSS, os trabalhos relacionaram as práticas sustentáveis de gestão de resíduos de serviços de saúde com o desenvolvimento de estratégias abrangentes que orientem as práticas de gestão de resíduos de serviços de saúde, instituindo deveres, responsabilidades e responsáveis pelo processo em todo seu fluxo de operação.

É necessário que os países desenvolvam estratégias abrangentes de gestão de resíduos, incluindo definições específicas do que constitui resíduos, deveres e responsabilidades claramente definidos para cada ator no processo de gestão, identificando uma autoridade nacional responsável pela supervisão, implementação da lei e sua aplicação incluindo penalidades específicas por contravenção (WALKINSHAW, 2011).

Awodele et al. (2016) em seu estudo, determinou o impacto da intervenção da autoridade de gestão de Resíduos, reforçando a necessidade de formulação de políticas e diretrizes.

A introdução de uma política escrita sobre a geração de resíduos demonstrou que a gestão eficaz pode reduzir custos e o risco para a saúde e ainda proteger o meio ambiente (ALMUNEEF; MEMISH, 2003).

Uma estratégia de gestão por etapas complementada com a política apropriada, orientação e execução a nível regional e nacional é sugerida por (ABDULLA et al., 2008).

Pouca atenção é dada à gestão de resíduos de serviços de saúde resultando uma falta de abordagem integrada para a formulação de políticas no mais alto nível de tomada de decisão. Há necessidade de formular uma legislação de gestão de resíduos de cuidados de saúde mais sustentável. Inovação e soluções de baixo custo podem ser desenvolvidas e implementadas para melhorar a eficiência dos recursos no manuseio deste complexo fluxo de resíduos (MANGA et al., 2011).

Outro tema importante apontado é com relação aos artigos para assistência à saúde constituídos de PVC, estes são o causador da liberação de dioxinas e furanos, que são substâncias extremamente tóxicas e carcinogênicas 
quando passa pelo processo de incineração, estudo sugere a substituição desta matéria prima para minimizar o impacto ambiental gerado (JANG et al., 2006).

Por fim, é necessário maior pesquisa e atenção para as consequências não intencionais do progresso tecnológico na prestação de assistência de saúde para abordar e entender a crescente ameaça à saúde pública em todo o mundo (HARHAY et al., 2009).

Apesar das demandas mundiais e da busca das organizações para atender o desenvolvimento de produtos sustentáveis, as empresas ainda precisam adotar a sustentabilidade de forma sistemática em suas estratégias, onde todas as partes devem ser consideradas (MATTIODA et al., 2013). Fernandes et al. (2016) propõe um método para integração do processo de desenvolvimento de produtos voltado para a sustentabilidade. $O$ método apresenta uma sequência lógica para promover a interação entre as definições da categoria do produto, e a seleção de design para estratégias ambientais e que aplicados no contexto do processo de gerenciamento de resíduos de serviços de saúde podem auxiliar no desenvolvimento de processos mais eficientes e antecipar a visualização dos pontos críticos e as melhorias que precisam ser solucionadas.

\section{CONCLUSÃO}

Este artigo apresentou as iniciativas de abordagem ambientalmente sustentável na gestão dos resíduos de serviços de saúde desenvolvidas nos três níveis de abrangência (hospitalar, regional e nacional) com ações pontuais de nível operacional no ambiente hospitalar até práticas abrangentes que envolve políticas públicas e legislação nacional.

As principais ações encontradas na literatura envolveram: capacitação, segregação, políticas públicas, tecnologia de tratamento, minimização, reutilização e reciclagem, monitoramento do gerenciamento de RSS, designação de responsável pelas atividades de gestão de RSS e investimento pelos governos, entre outras.

Diante dos resultados obtidos, observa-se que tais iniciativas têm sido desenvolvidas de forma isolada. A gestão de resíduos de serviços de saúde é um sistema complexo de dimensão mundial. Para garantir o sucesso das ações cada etapa do gerenciamento deve ser analisada, considerando suas particularidades, porém de maneira complementar às demais.

Os diversos atores envolvidos no processo de gerenciamento de RSS precisam estar integrados de forma que a soma dos esforços possa produzir resultados mais sólidos e consistentes, aliados à integração entre entidades locais, regionais e nacionais, pois cada elo deste sistema afeta e é afetado pelos demais.
Foi Identificado a necessidade de um maior aprofundamento nas pesquisas que apresentam soluções inovadoras em gestão de RSS e um processo que permita a troca de informações entre instituições e um governo com o objetivo de disseminar as melhores práticas e contribuir na redução do impacto ambiental gerado por esta atividade.

Por fim, os autores acreditam que seria fundamental a criação de um modelo de maturidade alinhado com as melhores práticas e legislações ambientais que permita o norteamento das ações de gerenciamento de RSS com foco na sustentabilidade deste sistema. E isto está sendo objeto de exploração futura.

\section{AGRADECIMENTOS}

Os autores gostariam de agradecer à Coordenação de Aperfeiçoamento de Pessoal de Nível Superior (CAPES), Conselho Nacional de Desenvolvimento Científico e Tecnológico (CNPq) e Pontifícia Universidade Católica do Paraná (PUCPR) pelo apoio financeiro desta pesquisa.

\section{REFERÊNCIAS}

ABDULLA, F.; $A B U, H . ; R A B I, A$. Site investigation on medical waste management practices in northern Jordan 28, 450-458, 2008. https://doi.org/10.1016/j. wasman.2007.02.035

ABRELPE. Recomendações para a Gestão de Resíduos Sólidos durante a pandemia de Coronavírus (COVID-19), 2020. https://abrelpe.org.br/abrelpe-no-combate-a-covid-19/ (acesso em 13.10.2020)

ALMUNEEF, M.; MEMISH, Z.A. Effective medical waste management: It can be done. Am. J. Infect. Control 31, 188-192, 2003. https://doi.org/10.1067/mic.2003.43 ALVES, S.B.; E SOUZA, A.C.S.; TIPPLE, A.F.V.; REZENDE, K.C.A.D.; DE RESENDE, F.R.; RODRIGUES, É.G.; PEREIRA, M.S. The reality of waste management in primary health care units in Brazil. Waste Manag. Res. 32, 4047, 2014. https://doi.org/10.1177/0734242X14543815

ANANTH, A.P.; PRASHANTHINI, V.; VISVANATHAN, $C$. Healthcare waste management in Asia. Waste Manag. 30, 154-161, 2010. https://doi.org/10.1016/j. wasman.2009.07.018

ASKARIAN, M.; HEIDARPOOR, P.; ASSADIAN, O. A total quality management approach to healthcare waste management in Namazi Hospital, Iran. Waste Manag. 30, 2321-2326, 2010. https://doi.org/10.1016/j. wasman.2010.06.020

ASKARIAN, M.; VAKILI, M.; KABIR, G. Results of a hospital waste survey in private hospitals in Fars 
province, Iran. Waste Manag. 24, 347-352, 2004. https://doi.org/10.1016/j.wasman.2003.09.008

AWODELE, O.; ADEWOYE, A.A.; OPARAH, A.C. Assessment of medical waste management in seven hospitals in Lagos, Nigeria 1-11, 2016. https:// doi.org/10.1186/s12889-016-2916-1

BENDJOUDI, Z.; TALEB, F.; ABDELMALEK, F.; ADDOU, A. Healthcare waste management in Algeria and Mostaganem department. Waste Manag. 29, 1383-1387, 2009. https://doi.org/10.1016/j. wasman.2008.10.008

BIANCO, B.; CHRISTOFOLINI, D.M.; SOUZA, Â.M.B. DE; BARBOSA, C.P. $O$ papel dos desreguladores endócrinos na fisiopatologia da endmetriose: revisão da literatura. Arq. Bras. Ciências da Saúde 35, 2010. https://doi.org/10.7322/abcs.v35i2.95

CANIATO, M.; TUDOR, T.; VACCARI, M. International governance structures for health-care waste management: A systematic review of scientific literature. J. Environ. Manage. 2015. https://doi.org/10.1016/j.jenvman.2015.01.039

CANIATO, M.; VACCARI, M.; VISVANATHAN, C.; ZURBRÜGG, C. Using social network and stakeholder analysis to help evaluate infectious waste management: A step towards a holistic assessment. Waste Manag. 34, 938-951, 2014. https://doi. org/10.1016/J.WASMAN.2014.02.011

CHENG, Y.W.; SUNG, F.C.; YANG, Y.; LO, Y.H.; CHUNG, Y.T.; $\mathrm{LI}, \mathrm{K}$. Medical waste production at hospitals and associated factors. Waste Manag. 29, 440-444, 2009. https://doi.org/10.1016/j.wasman.2008.01.014

COKER, A.; SANGODOYIN, A.; SRIDHAR, M.; BOOTH, C.; OLOMOLAIYE, P.; HAMMOND, F. Medical waste management in lbadan, Nigeria : Obstacles and prospects. Waste Manag. 29, 804-811, 2009. https://doi. org/10.1016/j.wasman.2008.06.040

CREPALDI, S.A. Auditoria Contábil Teoria e Prática, 6a. ed. SÃO PAULO, 2010.

EL-SALAM, M.M.A. Hospital waste management in El-Beheira Governorate, Egypt. J. Environ. Manage. 91, 618-629, 2010. https://doi.org/10.1016/j. jenvman.2009.08.012

FERNANDES, P.T.; CANCIGLIERI JÚNIOR, O.; SANT'ANNA, Â. M. O. Method for integrated product development oriented to sustainability. Clean Technologies and Environmental Policy, v. 19, n. 3, p. 775-793, 2017. Springer Berlin Heidelberg.

FERNÁNDEZ-RÍOS, L.; BUELA-CASAL, G. Standards for the preparation and writing of Psychology review articles. Int. J. Clin. Heal. Psychol. 9, 329-344, 2009. GUPTA, S.;BOOJH, R.;MISHRA, A.;CHANDRA, H. Rules and management of biomedical waste at Vivekananda Polyclinic: A case study. Waste Manag. 29, 812-819, 2009. https://doi.org/10.1016/j.wasman.2008.06.009

HARHAY, M.O.; HALPERN, S.D.; HARHAY, J.S.; OLLIARO, P.L. Health care waste management: a neglected and growing public health problem worldwide 14, 1414-1417, 2009. https://doi. org/10.1111/j.1365-3156.2009.02386.x

HOSSAIN, S.; SANTHANAM, A.; NORULAINI, N.A.N.; OMAR, A.K.M. Clinical solid waste management practices and its impact on human health and environment - A review. Waste Manag. 31, 754-766, 2011. https://doi.org/10.1016/j.wasman.2010.11.008 INSA, E.; ZAMORANO, M.; LÓPEZ, R. Critical review of medical waste legislation in Spain. Resour. Conserv. Recycl. 54, 1048-1059, 2010. https://doi.org/10.1016/J. RESCONREC.2010.06.005

JANG, Y.; LEE, C.; YOON, O.; KIM, H. Medical waste management in Korea. 80, 107-115, 2006. https://doi.org/10.1016/j.jenvman.2005.08.018

MANGA, V.E.; FORTON, O.T.; MOFOR, L.A.; WOODARD, $R$. Health care waste management in Cameroon: $A$ case study from the Southwestern Region. Resour. Conserv. Recycl. 57, 108-116, 2011. https://doi.org/10.1016/J.RESCONREC.2011.10.002

MATTIODA, R. A.; FERNANDES, P. T.; DETRO, S. P.; CASELA, J. L.; JUNIOR, O. C. Principle of triple bottom line in the integrated development of sustainable products. Chemical Engineering Transactions, v. 35, p. 199-204, 2013.

MATTIODA, R. A. A. ; FERNANDES, P. T. ; CASELA, J. L. ; CANCIGLIERI JUNIOR, O. ; MAZZI, A. . Thoughts on Product Development Oriented to Sustainability in Organizational Overview. Advanced Materials Research (Online), v. 1061, p. 1238-1244, 2015.

MATO, R.R.A.M.; KASEVA, M.E. Critical review of industrial and medical waste practices in Dar es Salaam City. Resour. Conserv. Recycl. 25, 271-287, 1999. https://doi.org/10.1016/S0921-3449(98)00068-8 RECHE, ALDA YOSHI UEMURA; CANCIGLIERI JUNIOR, O. ; ESTORILIO, C. C. A. ; RUDEK, M. . Integrated Product Development Process and Green Supply Chain Management: contributions, limitations and applications. JOURNAL OF CLEANER PRODUCTION , v. 246, p. 119429-119459, 2019.

RUME, T.; ISLAM, S. M. D. U. Environmental effects of COVID-19 pandemic and potential strategies 
of sustainability. Heliyon, v. 6, n. 9, p. e04965, 2020. Elsevier Ltd. Disponível em: <https://doi.org/10.1016/j. heliyon.2020.e04965>.

SOLIMAN, S.M.; AHMED, A.I. Overview of biomedical waste management in selected Governorates in Egypt : A pilot study, 2007. https://doi.org/10.1016/j. wasman.2006.08.009

SZEJKA, A. L. ; CANCIGLIERI JUNIOR, O. ; PANETTO, H. ; LOURES, E. R.; AUBRY, A. . Semantic interoperability for an integrated product development process: a systematic literature review. INTERNATIONAL JOURNAL OF PRODUCTION RESEARCH , v. 55, p. 1-19, 2017.

TEIXEIRA, G.F.G. ; CANCIGLIERI JUNIOR, O. . How to make Strategic Planning for Corporate Sustainability?. JOURNAL OF CLEANER PRODUCTION , v. 230, p. 1421-1431, 2019.

WALKINSHAW, E. Medical waste-management practices vary across Canada. Can. Med. Assoc. J. 183, E1307-E1308, 2011. https://doi.org/10.1503/ cmaj.109-4032

WINDFELD, E.S.; BROOKS, M.S.L. Medical waste management - A review. J. Environ. Manage, 2015. https://doi.org/10.1016/j.jenvman.2015.08.013

WOOLRIDGE, A.; MORRISSEY, A.; PHILLIPS, P.S. The development of strategic and tactical tools, using systems analysis, for waste management in large complex organisations: a case study in UK healthcare waste. 44, 115-137, 2005. https://doi.org/10.1016/j.resconrec.2004.11.001

WORLD HEALTH ORGANISATION; EMMANUEL, J.; PIEPER, U.; RUSHBROOK, P.; STRINGER, R.; TOWNEND, W.; WILBURN, S.; ZGHONDI, R. Safe management of wastes from health-care activities 329, 2014.

WORLD HEALTH ORGANIZATION. Dioxins and their effects on human health. 4 october 2016. Disponível em: http://www.who.int/news-room/fact-sheets/detail/dioxins-and-theireffects-on-human-health Acesso em 06/10/2020.

YANG, C.; PEIJUN, L.; LUPI, C.; YANGZHAO, S.; DIANDOU, X.; QIAN, F.; SHASHA, F. Sustainable management measures for healthcare waste in China. Waste Manag. 29, 1996-2004, 2009. https://doi.org/10.1016/j. wasman.2008.11.031

ZAMONER, M. Modelo para avaliação de planos de gerenciamento de resíduos de serviços de saúde (PGRSS) para Secretarias Municipais da Saúde e/ ou do Meio Ambiente. Ciênc. saúde coletiva [online]. 2008, vol.13, n.6, pp.1945-1952. ISSN 1678-4561. https://doi.org/10.1590/S1413-81232008000600030.

\section{AUTORES}

ORCID: 0000-0003-4447-0824

MÁRCIA REGINA CORDEIRO DE SOUZA | PPGEPS - Pontifícia Universidade Católica do Paraná (PUCPR) / Programa de Pós-Graduação em Engenharia de Produção e Sistemas (PPGEPS) / Curitiba - Paraná (PR) - Brasil | Correspondência para: Rua Imaculada Conceição, 1155, Prado Velho; CEP 80215-901| e-mail: marcia.mrc@gmail.com

\section{ORCID: 0000-0002-8503-9275}

OSÍRIS CANCIGLIERI JUNIOR, Phd. | Pontifícia Universidade Católica do Paraná (PUCPR) / Programa de Pós-Graduação em Engenharia de Produção e Sistemas (PPGEPS) / Curitiba - Paraná (PR) - Brasil | Correspondência para: Rua Imaculada Conceição, 1155, Prado Velho; CEP 80215-901; osiris.canciglieri@pucpr.br

\section{COMO CITAR ESTE ARTIGO}

SOUZA, Márcia Regina Cordeiro de; CANCIGLIERI Jr., Osíris. Práticas Ambientalmente Sustentáveis Em Gestão De Resíduos De Serviços De Saúde: Uma Revisão. MIX Sustentável, [S.I.], v. 7, n. 2, p.41-56, abr. 2021. ISSN 24473073. Disponível em:<http://www. nexos.ufsc.br/index.php/mixsustentavel>. Acesso em: dia mês. ano. doi:https://doi.org/10.29183/2447-3073. MIX2021.v7.n2.41-56.

DATA DE ENVI0: 08/07/2020

DATA DE ACEITE: 05/11/2020 
